\title{
An Additional Approach to Model Current Followers and Amplifiers with Electronically Controllable Parameters from Commercially Available ICs
}

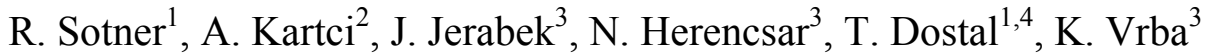 \\ ${ }^{1}$ Dept. of Radio Electronics, Faculty of Electrical Engineering and Communications, Brno University of Technology, \\ Purkynova 118, 612 00, Brno, Czech Republic, sotner@feec.vutbr.cz \\ ${ }^{2}$ Dept. of Electronics and Telecommunication Engineering, Corlu Engineering Faculty, Namik Kemal University, \\ Cerkezkoy, Yolu, 3. km, 59860 Corlu, Turkey, aslhankartc@gmail.com \\ ${ }^{3}$ Dept. of Telecommunications, Faculty of Electrical Engineering and Communications, Brno University of Technology, \\ Purkynova 118, 612 00, Brno, Czech Republic, \{jerabekj; herencsn; vrbak\}@feec.vutbr.cz \\ ${ }^{4}$ Dept. of Electronics and Computer Science, College of Polytechnics Jihlava, Tolsteho 16, 586 01, Jihlava, Czech Republic, \\ dostal@vspj.cz
}

\begin{abstract}
Several behavioral models of current active elements for experimental purposes are introduced in this paper. These models are based on commercially available devices. They are suitable for experimental tests of current- and mixed-mode filters, oscillators, and other circuits (employing current-mode active elements) frequently used in analog signal processing without necessity of onchip fabrication of proper active element. Several methods of electronic control of intrinsic resistance in the proposed behavioral models are discussed. All predictions and theoretical assumptions are supported by simulations and experiments. This contribution helps to find a cheaper and more effective way to preliminary laboratory tests without expensive on-chip fabrication of special active elements.
\end{abstract}

Keywords: Intrinsic resistance, current and voltage gain control, current follower and amplifier, behavioral modeling

\section{INTRODUCTION}

$\mathrm{M}$ ANY WORKS deal with specific applications of modern active elements [1]. Methods of intrinsic resistance adjusting (for example Fabre et al. [2], Siripruchyanun et al. [3]) by bias current in many novel and standard active elements are very popular. This kind of control was mainly the domain of current conveyors (CC-s) and its applications (Sedra et al. [4], Svoboda et al. [5]). However, this parameter (intrinsic resistance - labeled as $R_{\mathrm{i}}$ or $R_{\mathrm{x}}$ ) is given by technological aspects and is dependent on temperature. Some designers consider this parameter as parasitic. It is correct in some cases, mainly in active elements where the $R_{\mathrm{i}}$ value is not adjustable [5]. In addition, this resistance is considered as small-signal parameter. Behavior of $R_{\mathrm{i}}$ for higher signal levels has nonlinear character.

In the last three decades considerable attention was given to the active elements with electronic possibility of current gain control (Surakampontorn et al. [6], Fabre et al. [7], Minaei et al. [8]). It seems to be a very interesting topic for researchers. Some novel types of current conveyors (Mahmound et al. [9], Kumngern et al. [10]), so-called current followers and nullors (Sedighi et al. [11], Tangsrirat [12], Tangsrirat et al. [13]), have been published quite recently. Alzaher et al. [14, 15] and Koton et al. [16] utilized digital control of current gain in their active elements and applications. Current gain control received important attention also in more complicated active elements formed by basic functional components, for example current differencing buffed amplifier (CDBA) presented by Biolek et al. in [17] and [18], programmable current amplifier
(PCA) introduced by Herencsar et al. [19], current gain controlled current conveyor transconductance amplifier (CGCCCTA) discussed in [20], etc.

Some attempts to use several methods of control in frame of one active element have been solved in recent years. For example Marcellis et al. [21] proposed an approach to control current gain and voltage gain independently in frame of one active element. Kumngerng et al. [22] proposed an interesting conception of current conveyor with intrinsic resistance and current gain controlling possibilities. Similar approach was used in [23], where both methods of control were used in the so-called double current controlled current feedback amplifier (DCC-CFA). Jaikla et al. [24] implemented the so-called current controlled current differencing transconductance amplifiers (CCCDTA-s) where intrinsic resistance and transconductance [1] adjusting is possible.

Discussed approaches have been widely investigated in recent years. However, all discussed elements and approaches require fabrication of designed internal implementation or we have to rely only on simulation results. Nevertheless, experimental verification is necessary or beneficial in many cases. It provides a more realistic view on behavior of the proposed application. Experimental tests with available devices are more reliable despite the accuracy and exactness of some simulation results. However, fabrication of on-chip implementation is very expensive and therefore not suitable for preliminary tests of application in the most cases. Accessibility of specialized models used for realistic modeling seems to be an advantage for designers. Practically, precise models of active elements with exactly defined and controllable intrinsic resistance complemented 
by adjustable current gain are missing in available literature. Therefore in this paper we implemented and verified several conceptions of current followers and amplifiers. The first two solutions employ electronically controllable current conveyors (ECCII) and current gain control. The current gain $(B)$ is controllable by $\mathrm{DC}$ voltage. The second type utilizes voltage gain $(A)$ in voltage controllable voltage amplifier (VCA) and diamond transistor (DT).

\section{MODEL OF CURRENT FOLLOWERS AND AMPLIFIERS WITH ADJUSTABLE FEATURES}

General description and behavior of single-input and single-output (SISO) current follower (CF) with controllable intrinsic resistance $R_{\mathrm{i}}=f\left(V_{\mathrm{Ri}}\right)$ or current amplifier (CA) with controllable intrinsic resistance and current gain $k_{\mathrm{i}}=f\left(V_{\mathrm{ki}}\right)$ is shown in Fig.1.

Main reasons for the proposal of behavioral models are following:

a) This approach allows the design of application, experimental verification of features and optimization without fabrication of particular active element in phase of first tests, which is very economical.

b) There are not many ways in literature explaining how to model electronically controllable intrinsic resistance in real experimental tests without chip and fabrication.

c) Small-signal resistance $R_{\mathrm{i}}$ is suitable only for smallsignal operation in many cases. Our solution provides large range of input signals without significant increase of total harmonic distortion (THD).

d) Key features of models are independent on technology and fabrication process $\left(R_{\mathrm{i}}\right.$ parameter is defined by external components and control voltage). Only restrictions of gain control of active elements limit achievable $R_{\mathrm{i}}$ of the model. Many on-chip implementations have intrinsic resistance dependent on the technology used. This intrinsic resistance is controllable by bias voltage or current $[2,3]$. Nevertheless, adjusting of these bias values has negative effect on other parameters (output resistance, linearity, dynamic,...). In addition, temperature dependence of $R_{\mathrm{i}}$ is obvious. One example is the equation $R_{\mathrm{i}}=V_{\mathrm{t}} / 2 I_{\mathrm{b}}$ (known for Sedra's conveyor [4] and in similar form for many other works e.g. [2-3]) which is valid in BJT technology where $V_{\mathrm{t}} \approx 26 \mathrm{mV}$ is thermal voltage (temperature dependent), and $I_{\mathrm{b}}$ is bias current. In our models, intrinsic resistance is not directly defined by temperature-dependent parameter $\left(V_{t}\right)$. Therefore, in our case the dependence on fabrication technology is not so important.

\section{A. Adjustable Current Followers and Amplifiers based on Controllable Current Gains}

The first part of this work deals with utilization of a negative-type electronically controllable second generation current conveyor (ECCII-). Behavior of ECCII- is explained in Fig.2. The transfers between terminal voltages and currents are as follows (Surakampontorn et al. [6]; Minaei et al. [8]): $V_{\mathrm{Y}}=V_{\mathrm{X}}+R_{\mathrm{X}} \cdot I_{\mathrm{X}}, I_{\mathrm{Y}}=0, I_{\mathrm{Z}-}=-B \cdot I_{\mathrm{X}}$, where $R_{\mathrm{X}}$ is intrinsic resistance of ECCII- $[4,5] . R_{\mathrm{x}}$ has fixed value in this case, therefore it is considered as parasitic element. There is no possibility to change the value of $R_{\mathrm{x}}$ electronically, except by bias current [2,3] in some integrated implementation, but it is not generally valid for all cases of CCIIs $[4,5]$.

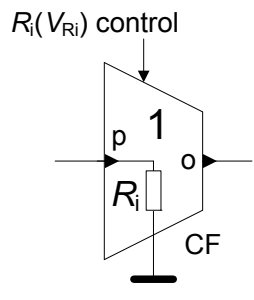

a)

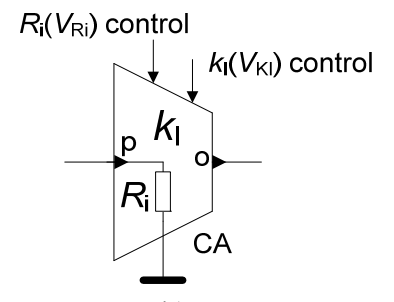

b)
Fig.1. Symbol of: a) the current follower with only input resistance control, b) the current amplifier with current gain and input resistance control.

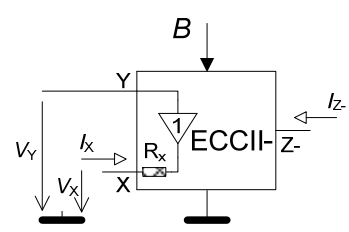

Fig.2. Symbol of ECCII-.

\section{1) Solution Employing Two External Resistors}

The possible conception of the inverting CF (CA) utilizing ECCII- and employing two resistors is depicted in Fig.3. The first section of the circuit in Fig.3 (without $\mathrm{CC}_{3}$ ) represents simple non-inverting $\mathrm{CF}$ with controllable intrinsic resistance (at $p$ terminal). Note that this part could be used independently, because in some applications only $\mathrm{CF}$ is sufficient instead of the whole current amplifier. The input resistance is defined as $R_{\mathrm{i}}=R_{1} / B_{1}$. If the whole structure from Fig.3 is considered, overall current gain has the following form:

$$
k_{i}=-\frac{B_{2} B_{3}}{B_{1}} \frac{R_{1}}{R_{2}}
$$

Assuming $B_{1}=B_{2}$ (adjusting of $B_{1}$ only in order to change $R_{\mathrm{i}}$ value causes unintentional affection on $k_{\mathrm{i}}$ - therefore simultaneous control of both $B$ ) and $R_{1}=R_{2}$, the overall current gain in Eq. (1) simplifies to $k_{\mathrm{i}}=-B_{3}$. Effects of the non-ideal properties $\left(R_{\mathrm{x} 1}, R_{\mathrm{x} 2}, R_{\mathrm{x} 3}\right)$ cause minor modification of adjustable intrinsic resistance:

$$
R_{i}=\frac{\left(R_{1}+R_{x 1}\right)}{B_{1}} .
$$

Now, the current transfer including the discussed nonidealities has the following form:

$$
k_{i}=-\frac{B_{2} B_{3}}{B_{1}} \frac{\left(R_{1}+R_{x 1}\right)}{\left(R_{2}+R_{x 2}\right)},
$$

where we have to ensure that $R_{1}=R_{2}$ and $R_{1,2}>R_{\mathrm{x} 1,2}$, if no significant impact on gain is required. The output impedance (resistance) of $\mathrm{CC}_{2}$ has multiple times higher value than $R_{\mathrm{x} 3}$. 
One disadvantage of such approach is the necessity of simultaneous change of both current gains $\left(B_{1}\right.$ and $\left.B_{2}\right)$ for $R_{\mathrm{i}}$ control without impact on current gain.

\section{2) Solution Employing One External Resistor}

The next interesting type including ECCII- is shown in Fig.4a. This variant is also easily applicable as controlled negative resistor, if the outputs of $\mathrm{CC}_{1}$ and $\mathrm{CC}_{2}$ are swapped (see Fig.4b). The $\mathrm{CC}_{3}\left(B_{3}\right)$ is necessary only for current gain control. It is obvious that this model also works as $\mathrm{CF}$ with controllable $R_{\mathrm{i}}$ without $\mathrm{CC}_{3}$. Input resistance of the $p$ terminal is given by $R_{\mathrm{i}}=R_{1} / B_{1}$ (similarly as in previous case) and current gain has the form $k_{\mathrm{i}}=B_{2} B_{3} / B_{1}$. Simultaneous change of both $B_{1}$ and $B_{2}$ is also required for operation without influence on overall $k_{\mathrm{i}}$.

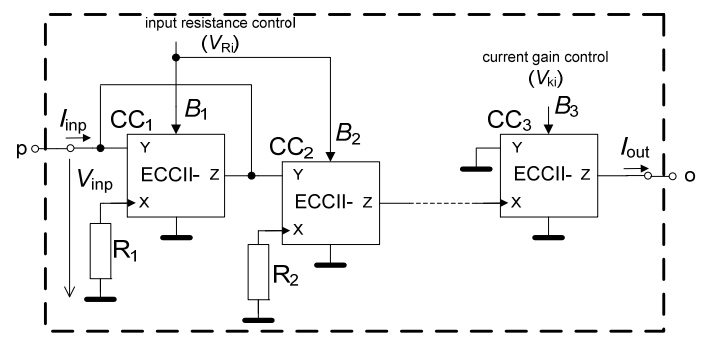

Fig.3. Solution employing two external resistors.

a)

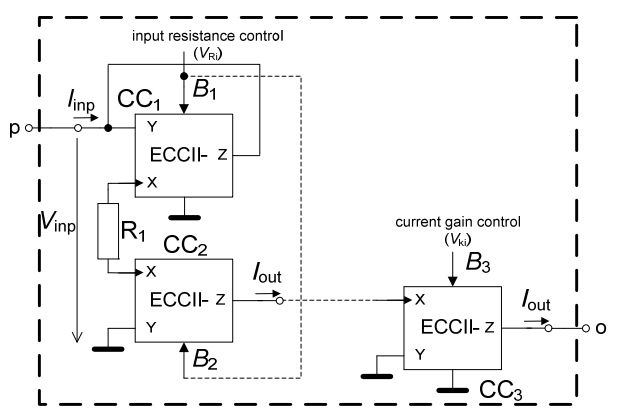

b)

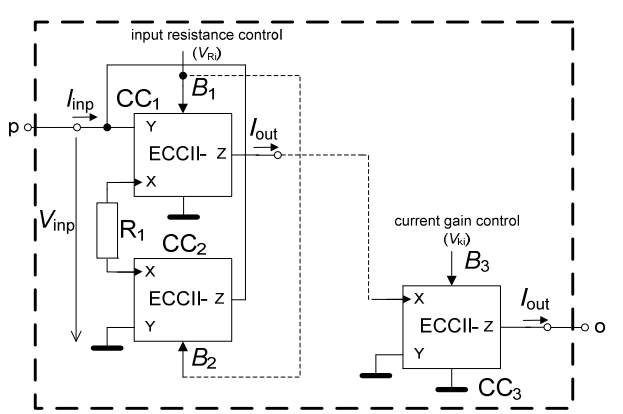

Fig.4. Solution employing one external resistor: a) for positive $R_{\mathrm{i}}$ value adjusting, b) for negative $R_{\mathrm{i}}$ value adjusting.

Considering the $R_{\mathrm{x}}$ of both $\mathrm{CC}_{1}$ and $\mathrm{CC}_{2}$, the input resistance can be expressed as:

$$
R_{i}= \pm \frac{\left(R_{1}+R_{x 1}+R_{x 2}\right)}{B_{1}}
$$

It is obvious that $R_{\mathrm{i}}$ is more dependent on input resistances of partial CCs $\left(R_{\mathrm{x} 1,2}\right)$ than in the previous case.

\section{B. Adjustable Current Amplifiers Based on Controllable Voltage Gains}

Two interesting solutions are given in this part of our work. Main core of models consists of two voltage controllable amplifiers (VCA) and diamond transistor (DT). Their schematic symbols are shown in Fig.5. The voltage controllable amplifier with differential input and single output is defined by well-known equation: $V_{\text {out }}=\left(V_{+}-V_{-}\right) A$, where $A=f\left(V_{\mathrm{c}}\right)$. The principle of the diamond transistor is very similar to the second generation current conveyor $[4$, 5]. Transfers between terminal (E - current input, B voltage input, $\mathrm{C}$ - current output) voltages and currents are ideally very similar to the CCII: $V_{\mathrm{B}}=V_{\mathrm{E}}, I_{\mathrm{B}}=0$, and $I_{\mathrm{C}}=I_{\mathrm{E}}$.

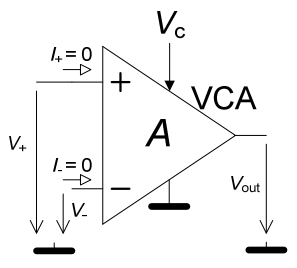

a)

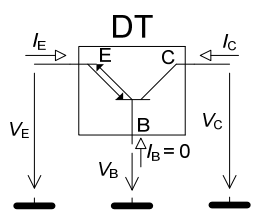

b)
Fig.5. Symbols of: a) voltage controllable amplifier, b) diamond transistor.

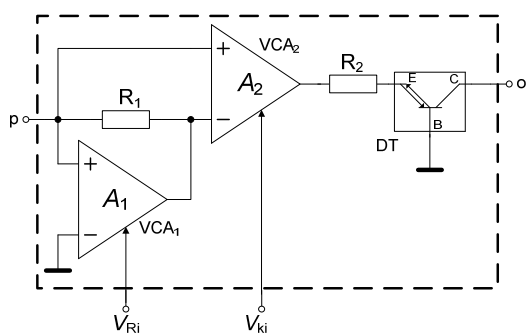

a)

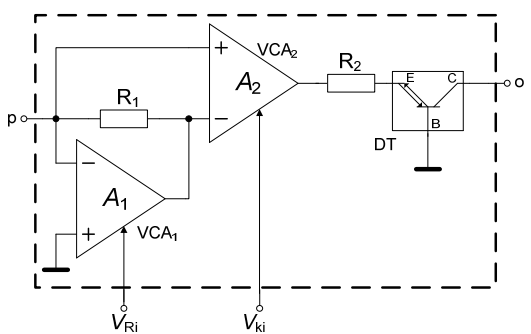

b)

Fig.6. Solution utilizing VCA and DT where $R_{\mathrm{i}}$ could be adjusted to be: a) positive and negative, b) positive only.

\section{1) Solution Using Two VCAs and one DT}

The models shown in Fig.6 are based on voltage-mode operation. The $\mathrm{VCA}_{1}$ has feedback resistor $R_{1}$ between positive input and output. Voltage drop at resistor $R_{1}$ is processed by differential input of the $\mathrm{VCA}_{2}$. The $\mathrm{VCA}_{2}$ provides voltage output and, therefore, conversion to the current mode is necessary. This conversion is made by DT through resistor $R_{2}$. Intrinsic resistance of the $p$ port of both solutions from Fig. 6 is defined by the following equations: 


$$
R_{i}=\frac{R_{1}}{1-A_{1}}, \quad R_{i}=\frac{R_{1}}{1+A_{1}} .
$$

Equation (5) is valid for solution shown in Fig.6a and Eq. (6) for the solution in Fig.6b. The circuit in Fig.6a provides interesting features (curiosity) in electronic control of $R_{\mathrm{i}}$. Intrinsic resistance has positive character for $A_{1}<1$. The value of $R_{\mathrm{i}}$ increases if $A_{1}$ is nearly equal to 1 . For higher values of $A_{1}$ the $R_{\mathrm{i}}$ value decreases and the whole input resistance is negative. However, the circuit is not stable for $A_{1}>1$. Overall current transfer of both solutions is given by:

$$
k_{i}=-\frac{R_{1}}{R_{2}} A_{2} .
$$

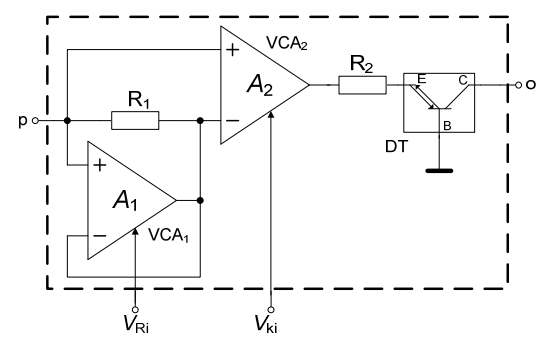

a)

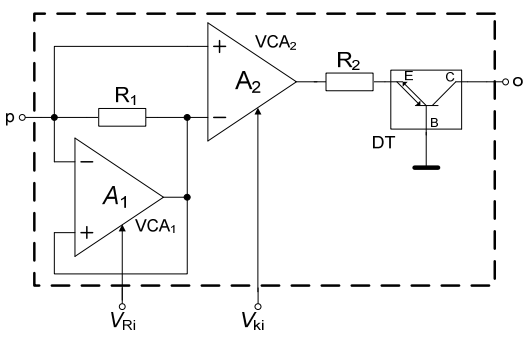

b)

Fig.7. Solution utilizing VCA and DT with additional feedback where $R_{\mathrm{i}}$ could be adjusted to be: a) positive only, b) positive and negative.

Adjustable gain of $\mathrm{VC}_{2}\left(A_{2}\right)$ allows electronic current gain control. In comparison to previous solutions with ECCII-s, the simultaneous change of two parameters is not necessary.

\section{2) Solution Using Two VCAs, one DT and Additional Voltage Feedback}

Modifications of circuits from Fig.6 were obtained when additional feedback was used. Modified version is shown in Fig.7. In this case the inverting input of $\mathrm{VCA}_{1}$ is not grounded but connected to the output of $\mathrm{VCA}_{1}$.

Presented modifications (Fig.7) provide following equations for $R_{\mathrm{i}}$ :

$$
R_{i}=R_{1}\left(1+A_{1}\right), R_{i}=R_{1}\left(1-A_{1}\right) .
$$

Equation (8) is valid for solution shown in Fig.7a and Eq. (9) for Fig.7b. Circuit in Fig.7a allows only increase of $R_{\mathrm{i}}$ values but solution in Fig.7b (interchanged terminals of $\mathrm{VCA}_{1}$ ) allows similar type of control as the conception in Fig.6a. Unfortunately, the amplifier is then unstable. Current gain of the whole model is the same as in the previous case (7).

\section{VERIFICATION AND PRACTICALLY ACHIEVABLE PERFORMANCES}

All the above discussed models of CF (CA) were verified experimentally. An experimental board was designed for these purposes. Measuring setup for experimental verification was established. The voltage to current and current to voltage converters were necessary at the input and output of the device under test (DUT). The grounded resistance $\left(R_{\mathrm{k} 2}\right)$ and voltage buffer was sufficient at the output, and voltage follower and resistor $\left(R_{\mathrm{k} 1}\right)$ were required for input conversion, see Fig.8. We used very good highspeed voltage followers OPA633 [25] or BUF634 [26]. This equipment allows measurement with vector/spectral network analyzer ( $50 \Omega$ matching). The transfer function has to be recalculated from voltage transfer which is measured by vector-network analyzer Agilent E5071C.

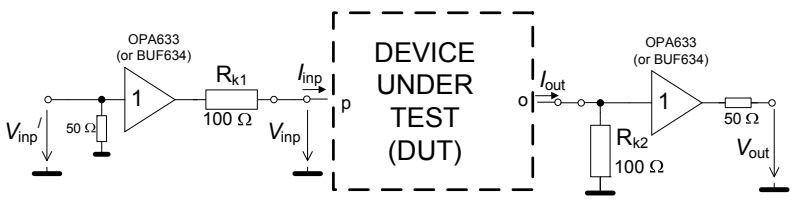

Fig.8. Measuring setup (testing equipment) for experimental tests.

Proper current transfers were recalculated from the following equations:

$$
\begin{gathered}
I_{\text {inp }}=\frac{V_{\text {inp }}^{\prime}}{R_{k 1}+R_{i}}, \quad I_{\text {out }}=\frac{V_{\text {out }}}{R_{k 2}}, \\
K_{I}=\frac{\frac{V_{\text {out }}}{R_{k 2}}}{\frac{V_{\text {inp }}^{\prime}}{R_{k 1}+R_{i}}}=\frac{V_{\text {out }}}{V_{\text {inp }}^{\prime}} \frac{R_{k 1}+R_{i}}{R_{k 2}}=K_{V} \frac{R_{k 1}+R_{i}}{R_{k 2}} .
\end{gathered}
$$

It is obvious that if $R_{\mathrm{k} 1}=R_{\mathrm{k} 2}=R_{\mathrm{k}}$, then Eq. (12) reduces to:

$$
K_{I}=K_{V}\left(1+\frac{R_{i}}{R_{k}}\right)
$$

\section{A. Adjustable Current Followers or Amplifiers Based on Controllable Current Gains}

\section{1) Solution Employing Two External Resistors}

Solution shown in Fig.3 was built by three EL2082-s [27] (current mode multiplier) as ECCII-s. Current gain $B$ is proportional to $\mathrm{DC}$ control voltage (and equal in range from 0 to $2 \mathrm{~V}$ ). For current gain and intrinsic resistance the following relations are valid:

$$
k_{i} \cong-V_{k i} \frac{\left(R_{1}+R_{x 1}\right)}{\left(R_{2}+R_{x 2}\right)}, \quad R_{i} \cong \frac{\left(R_{1}+R_{x 1}\right)}{V_{R i}} .
$$

Following values of passive elements: $R_{1}=R_{2}=220 \Omega$ $\left(R_{\mathrm{x} 1,2}=95 \Omega\right.$ [27]) were selected. Experimental results are summarized in Fig.9 - Fig.12. Magnitude responses for 
different values of current gain controlled by $V_{\mathrm{ki}}\left(B_{2} \approx V_{\mathrm{ki}}\right)$ and dependence of current gain $k_{\mathrm{i}}$ on control voltage $V_{\mathrm{ki}}$ are shown in Fig.9.

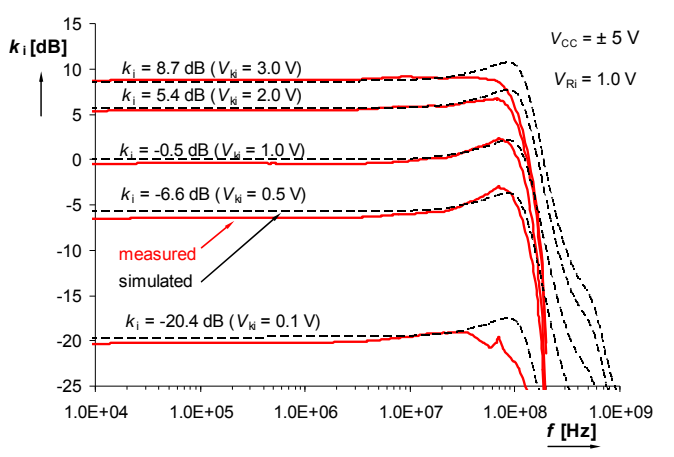

a)

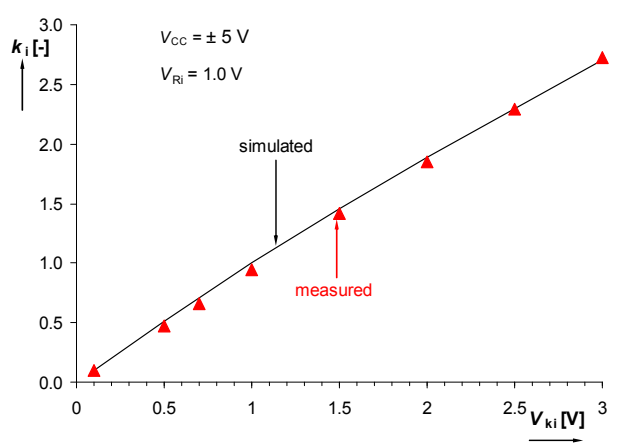

b)

Fig.9. Measured and simulated results: a) current gain magnitude response, b) dependence of current gain on control voltage.

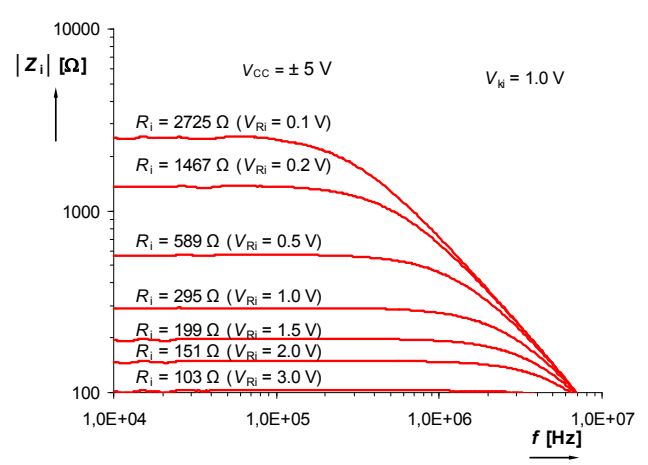

a)

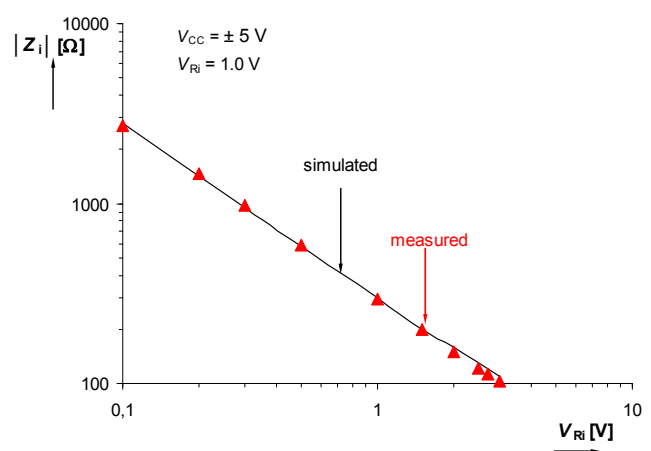

b)

Fig.10. Experimental results: a) measured frequency dependence of intrinsic resistance, b) dependence of intrinsic resistance on control voltage.

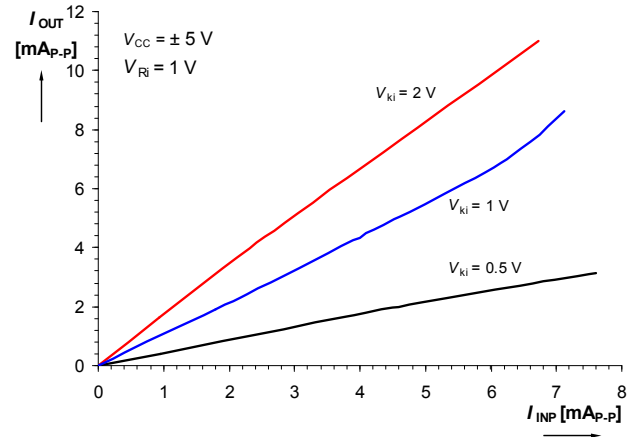

a)

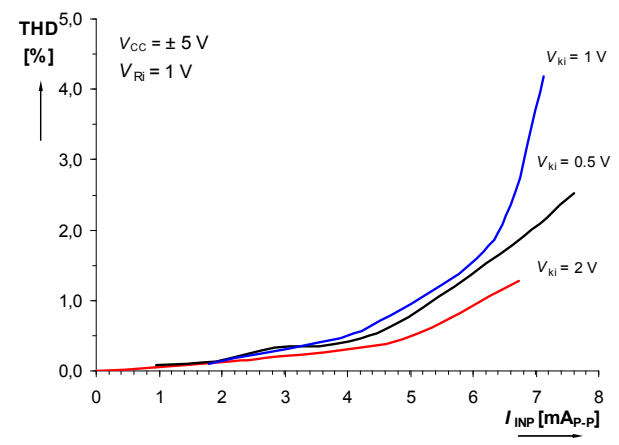

b)

Fig.11. Experimental results for harmonics excitation (1 MHz): a) measured dynamical characteristics, b) THD dependence on input level.

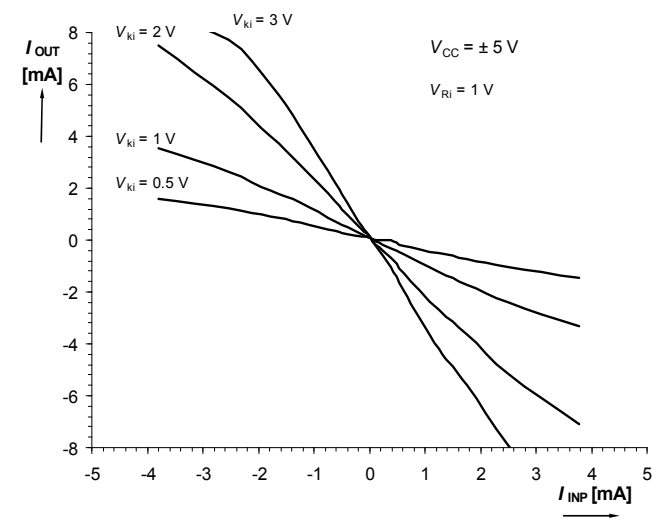

a)

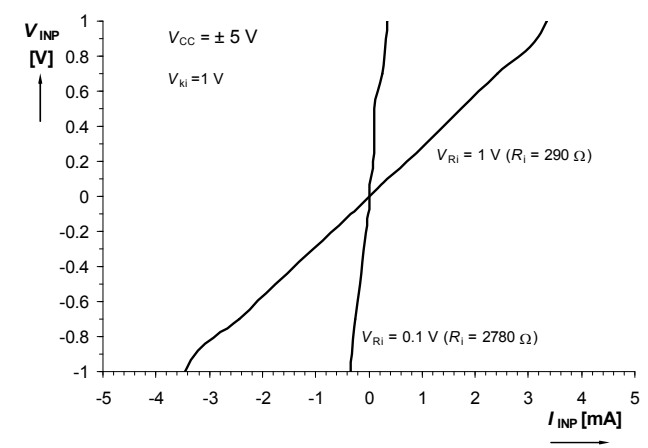

b)

Fig.12. Measured DC characteristics: a) $I_{\text {out }}$ vs. $I_{\text {inp }}$, b) $V_{\text {inp }}$ vs. $I_{\text {inp }}$ for $R_{\mathrm{i}}$ calculation. 
Fig.10 shows frequency dependence of the intrinsic resistance $\left(R_{\mathrm{i}}\right)$ and dependence of $R_{\mathrm{i}}\left(\left|Z_{\mathrm{i}}\right|\right.$ at $10 \mathrm{kHz}$ respectively) on control voltage $V_{\mathrm{Ri}}$. These results were obtained by network analyzer. However, capacity of the coaxial cable influences overall value of parasitic capacitance of current input $(p)$ for higher values of $R_{\mathrm{i}}$. Therefore, frequency bandwidth (flatness) of the $R_{\mathrm{i}}$ is lower than in the case where input terminal $(p)$ is directly connected to another analog system on printed circuit board. Nevertheless, results confirm workability of the proposed CA model.

Dynamical characteristics and dependence of total harmonic distortion (THD) on input current level (recalculated from voltage) for harmonic excitation (sine wave) are given in Fig.11. THD seems to be maximally $0.2 \%$ for amplitude lower than $0.5 \mathrm{~mA}$.

Static DC characteristics of CA and dependence of $V_{\text {inp }}$ on $I_{\text {inp }}$ for $R_{\mathrm{i}}$ calculation from DC values (traces for two $R_{\mathrm{i}}$ values are depicted) are shown in Fig.12.

\section{2) Solution Employing One External Resistor}

Current mode multipliers EL2082 were used also for the solution depicted in Fig.4a $\left(R_{1}=100 \Omega, R_{\mathrm{x} 1,2}=95 \Omega\right.$ [27]). Equations for current gain $k_{\mathrm{i}}$ and intrinsic resistance $\left(R_{\mathrm{i}}\right)$ have forms:

$$
k_{i} \cong V_{k i}, \quad R_{i} \cong \frac{\left(R_{1}+R_{x 1}+R_{x 2}\right)}{V_{R i}} .
$$

The current gain $k_{\mathrm{i}}$ is not dependent and influenced by $R_{1}$ or both parasitic intrinsic resistances of ECCII-s $\left(R_{\mathrm{x} 1,2}\right)$, which is an important advantage in comparison to the previous case. Nevertheless, we have to consider $R_{\mathrm{x} 1,2}$ which increase resulting $R_{\mathrm{i}}$ twice more in comparison with the previous solution. Results are presented in Fig.13 - Fig.16.

\section{B. Adjustable Current Amplifiers Based on Controllable Voltage Gains \\ 1) Solution Using Two VCAs and One DT}

Solution employing voltage controllable (voltage mode) amplifiers (VCA-s) and diamond transistor is better from the electronic control point-of-view. Main advantage is that no matching condition is necessary. External resistors have values $R_{1}=R_{2}=100 \Omega$. Two voltage controllable amplifiers VCA810 [28] and one diamond transistor OPA860 [29] were used in the solution depicted in Fig.6a. Following formulas for $k_{\mathrm{i}}$ and $R_{\mathrm{i}}$ are valid in accordance to [28]:

$$
k_{i} \cong-\frac{R_{1}}{R_{2}} 10^{-2\left(V_{k i}+1\right)}, \quad R_{i} \cong \frac{R_{1}}{1-10^{-2\left(V_{R i}+1\right)}} .
$$

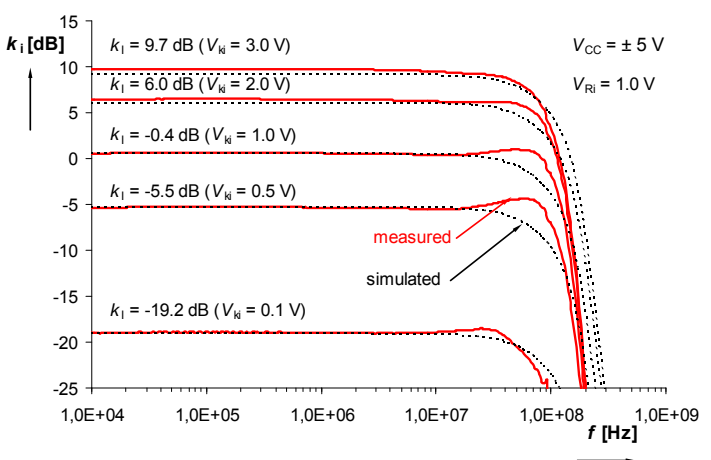

a)

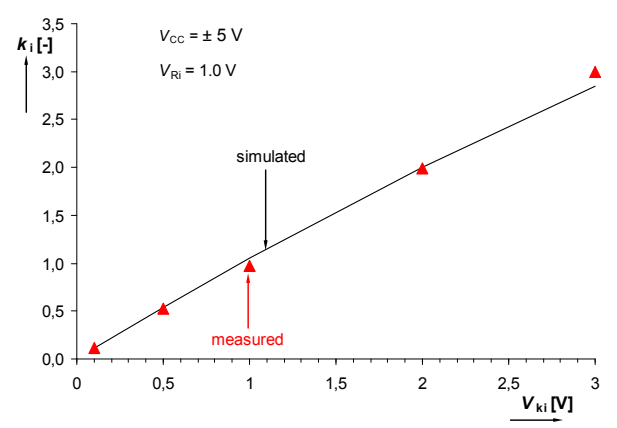

b)

Fig.13. Measured and simulated results: a) current gain magnitude response, b) dependence of current gain on control voltage.

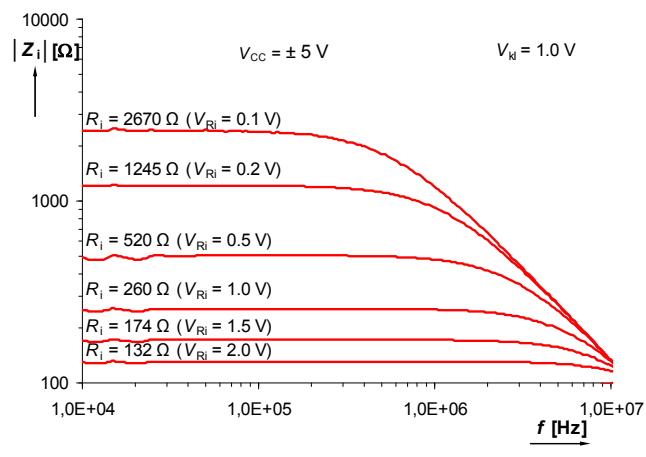

a)

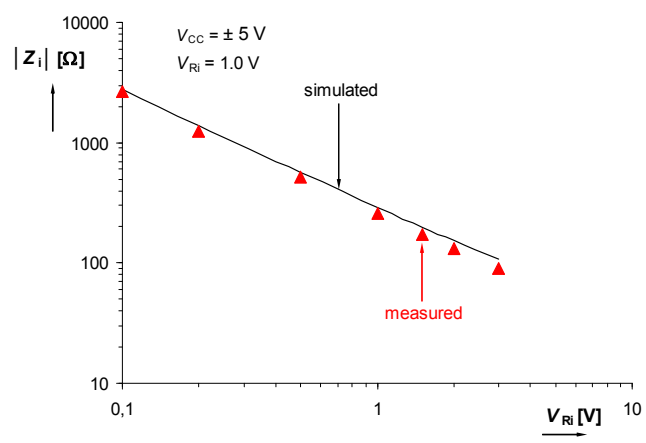

b)

Fig.14. Experimental results: a) measured frequency dependence of intrinsic resistance, b) dependence of intrinsic resistance on control voltage. 


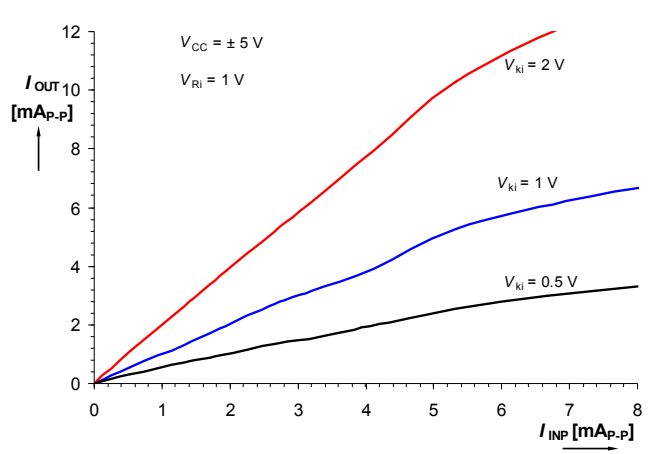

a)

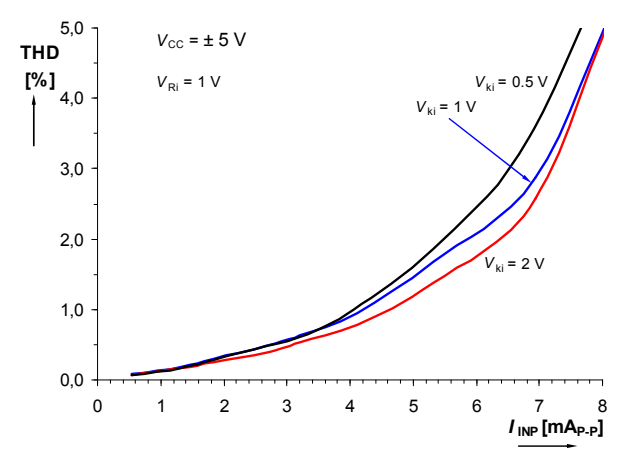

b)

Fig.15. Experimental results for harmonics excitation (1 MHz): a) measured dynamical characteristics, b) THD dependence on input level.

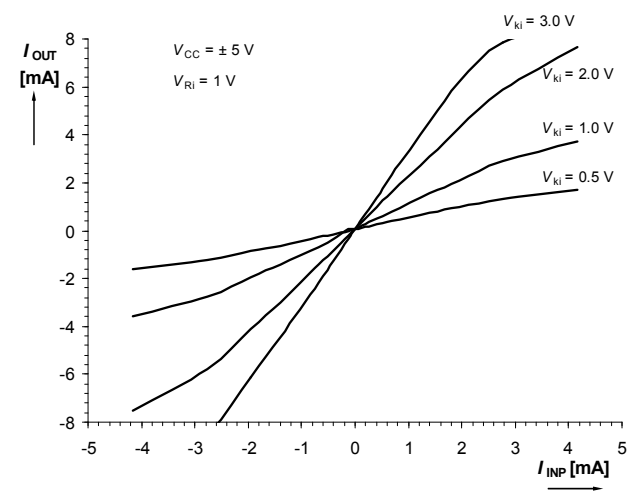

a)

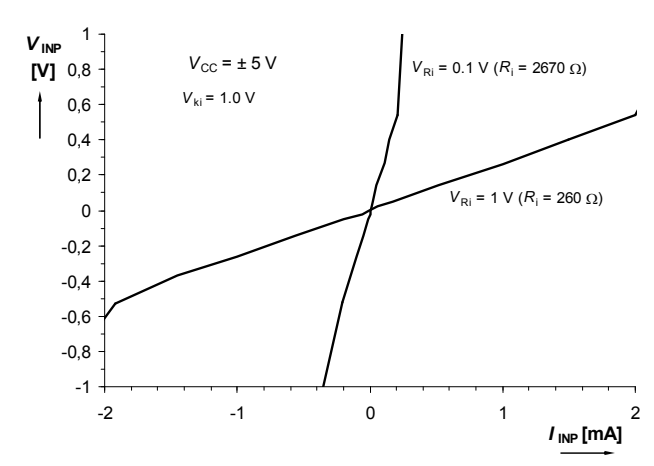

b)

Fig.16. Measured DC characteristics: a) $I_{\text {out }}$ vs. $I_{\text {inp }}$, b) $V_{\text {inp }}$ vs. $I_{\text {inp }}$ for $R_{\mathrm{i}}$ calculation.

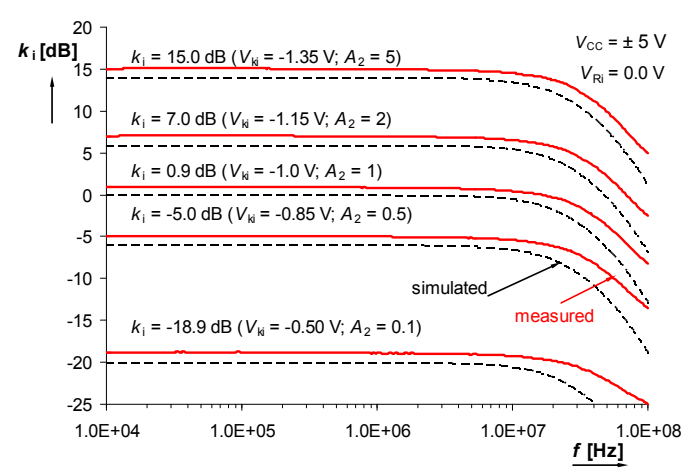

a)

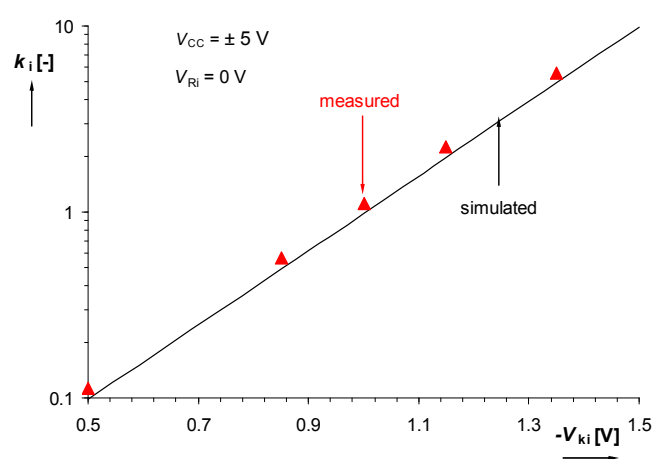

b)

Fig.17. Measured and simulated results: a) current gain magnitude response, b) dependence of current gain on control voltage.

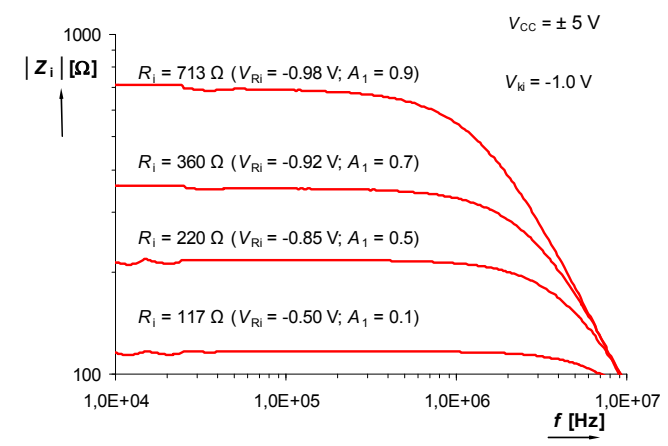

a)

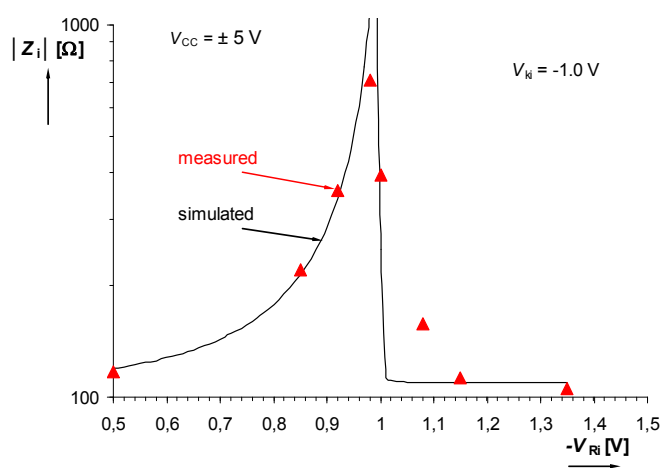

b)

Fig.18. Experimental results: a) measured frequency dependence of intrinsic resistance, b) dependence of intrinsic resistance on control voltage. 


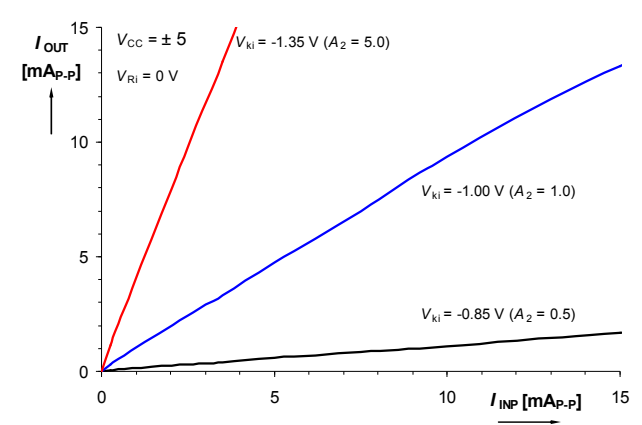

a)

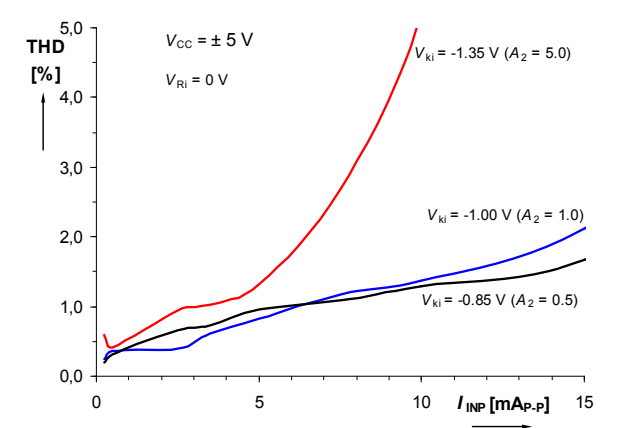

b)

Fig.19. Experimental results for harmonics excitation: a) measured dynamical characteristics, b) THD dependence on input level.

Results are shown in Fig.17 - Fig.20. Change of the resistance $R_{\mathrm{i}}$ is documented in Fig.18. The value increases till $V_{\mathrm{Ri}}$ achieves value close to $1 \mathrm{~V}$. If $V_{\mathrm{Ri}}$ gets over $1 \mathrm{~V}$, resistance decreases and it has negative character.

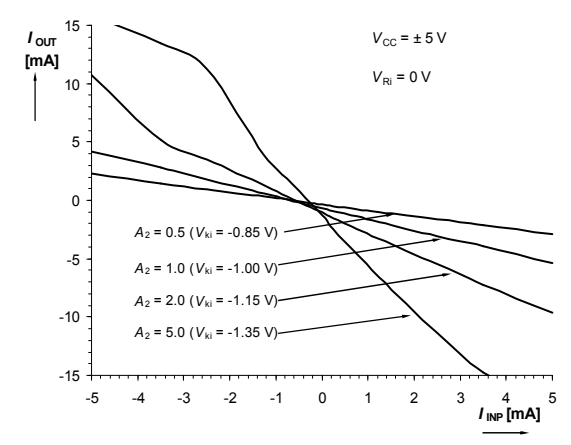

a)

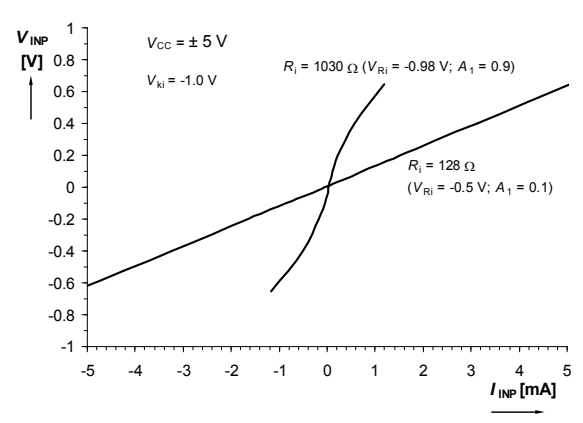

b)

Fig.20. Measured DC characteristics: a) $I_{\text {out }}$ vs. $I_{\text {inp }}$, b) $V_{\text {inp }}$ vs. $I_{\text {inp }}$ for $R_{\mathrm{i}}$ calculation.

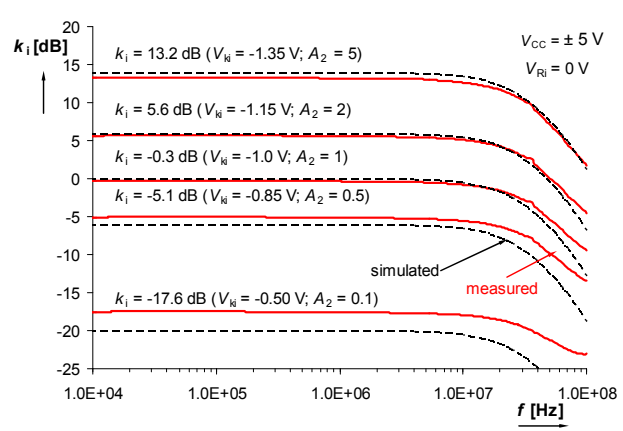

a)

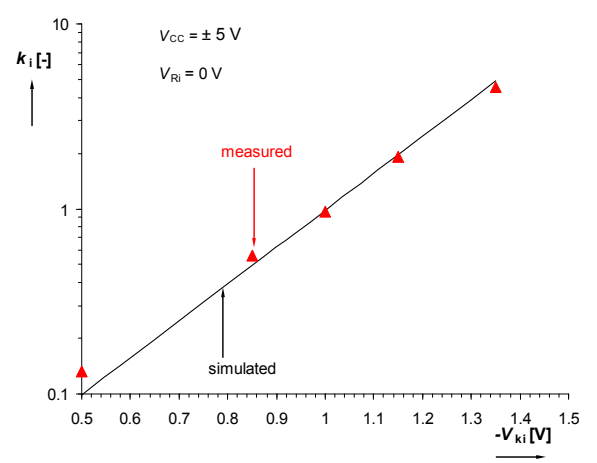

b)

Fig.21. Measured and simulated results: a) current gain magnitude response, b) dependence of current gain on control voltage.

\section{2) Solution Using Two VCAs, One DT and Additional Voltage Feedback}

The last presented solution (Fig.7a) was also built with VCA810 and OPA860 and specific equation valid for $R_{\mathrm{i}}$ of this type of CA has the form:

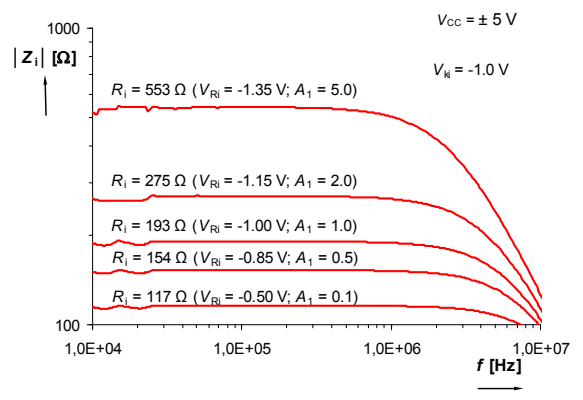

a)

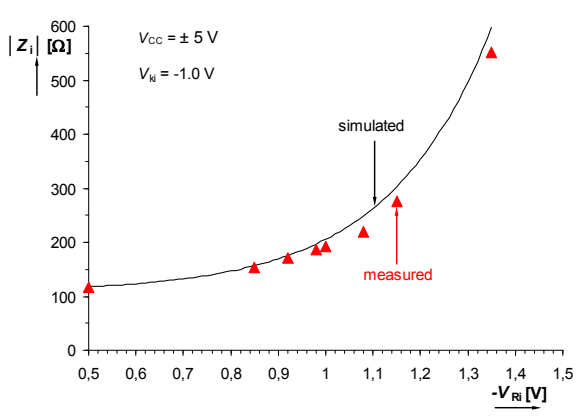

b)

Fig.22. Experimental results: a) measured frequency dependence of intrinsic resistance, b) dependence of intrinsic resistance on control voltage. 


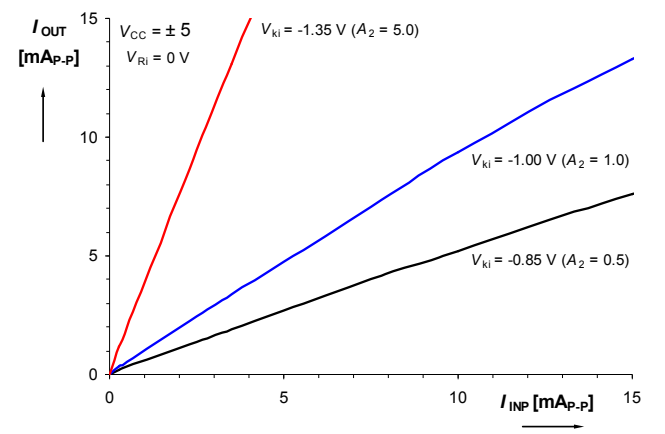

a)

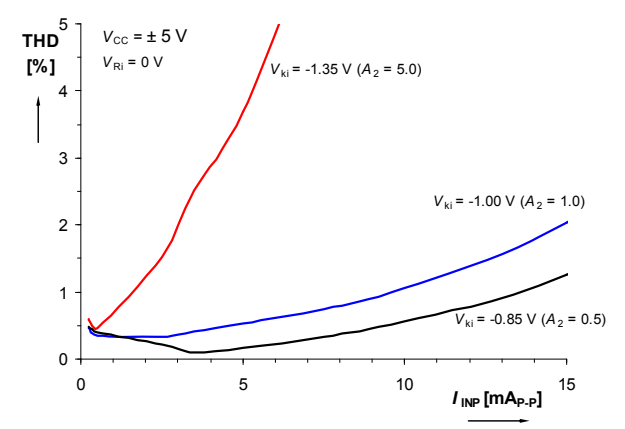

b)

Fig.23. Experimental results for harmonics excitation: a) measured dynamical characteristics, b) THD dependence on input level.

$$
R_{i} \cong R_{1}\left(1+10^{-2\left(V_{R i}+1\right)}\right)
$$

The current gain $k_{\mathrm{i}}$ has the same form as (18). Results are presented in Fig.21 - Fig.24.

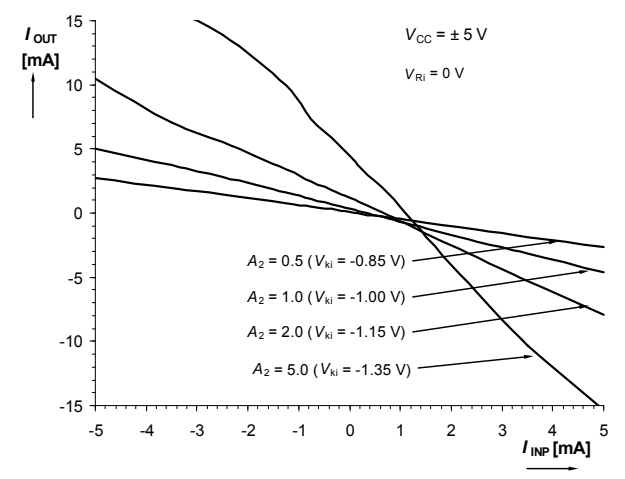

a)

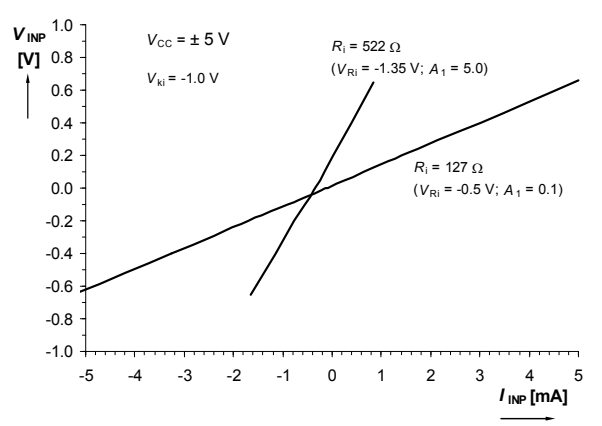

b)

Fig.24. Measured DC characteristics: a) $I_{\text {out }}$ vs. $I_{\text {inp }}$, b) $V_{\text {inp }}$ vs. $I_{\text {inp }}$ for $R_{\mathrm{i}}$ calculation.
Table 1. Comparison of main features of proposed solutions

\begin{tabular}{|c|c|c|c|c|}
\hline Solution & Fig. 3 & Fig. 4a & Fig. 6a & Fig. 7a \\
\hline $\begin{array}{l}\text { No. passive } \\
\text { elements }\end{array}$ & 2 grounded & 1 floating & 2 floating & 2 floating \\
\hline $\begin{array}{l}\text { No. active } \\
\text { elements }\end{array}$ & 3 ECCII-s & 3 ECCII-s & 2 VCA, DT & $2 \mathrm{VCA}, \mathrm{DT}$ \\
\hline $\begin{array}{l}\text { Matching of } \\
\text { parameters } \\
\text { required }\end{array}$ & yes & yes & no & no \\
\hline $\begin{array}{c}k_{\mathrm{i}} \mathrm{GBW} \\
{[\mathrm{MHz}]}\end{array}$ & $100-140$ & $70-110$ & $35-45$ & $25-45$ \\
\hline$k_{\mathrm{i}}[-]$ & $\begin{array}{c}0.1-2.7 \\
V_{\mathrm{ki}}(0.1-3 \mathrm{~V})\end{array}$ & $\begin{array}{c}0.1-2.8 \\
V_{\mathrm{ki}}(0.1-3 \mathrm{~V})\end{array}$ & $\begin{array}{c}0.1-5.6 \\
V_{\mathrm{ki}}(0.5-1.35 \mathrm{~V})\end{array}$ & $\begin{array}{c}0.1-4.6 \\
V_{\mathrm{ki}}(0.5-1.35 \mathrm{~V})\end{array}$ \\
\hline$R_{\mathrm{i}}[\mathrm{k} \Omega]$ & $\begin{array}{c}2.7-0.1 \\
V_{\mathrm{Ri}}(0.1-3 \mathrm{~V})\end{array}$ & $\begin{array}{c}2.7-0.13 \\
V_{\mathrm{Ri}}(0.1-2 \mathrm{~V})\end{array}$ & $\begin{array}{c}0.11-0.71 \\
V_{\mathrm{Ri}}(0.5-0.98 \mathrm{~V})\end{array}$ & $\begin{array}{c}0.16-0.55 \\
V_{\mathrm{Ri}}(0.5-1.35 \mathrm{~V})\end{array}$ \\
\hline $\begin{array}{l}\text { Type of } k_{\mathrm{i}} \\
\text { control }\end{array}$ & linear & linear & exponential & exponential \\
\hline $\begin{array}{l}\text { Type of } R_{\mathrm{i}} \\
\text { control }\end{array}$ & hyperbolic & hyperbolic & $\begin{array}{l}\text { hyperbolic/ } \\
\text { exponential }\end{array}$ & exponential \\
\hline
\end{tabular}

\section{Comparison of Proposed Solutions}

All presented and measured solutions are compared in Table 1. Number of active and passive elements, necessity of matching of parameters (for example $B_{1}=B_{2}$ in Fig. 3 and Fig.4a), gain bandwidth ( $-3 \mathrm{~dB})$, range of $k_{\mathrm{i}}$, input resistance $R_{\mathrm{i}}$, and type of control are the main attributes of the comparison. The solution from Fig. 3 requires three ECCII-s and two grounded resistors for adjusting of $k_{\mathrm{i}}$ and $R_{\mathrm{i}}$. The solution from Fig.4a provides the same benefits, but it consists of only one resistor. Frequency features and range of control of both important parameters $\left(R_{\mathrm{i}}, k_{\mathrm{i}}\right)$ for selected values $\left(R_{1}, R_{2}\right)$ are similar. The most important drawback of the first solution is influence of intrinsic resistances of ECCII $\left(R_{\mathrm{x} 1,2}\right)$ and external resistors $R_{1}$ and $R_{2}$ on $k_{\mathrm{i}}$. This drawback was removed in model of CA from Fig.4a, where only one resistor is required. The worst disadvantage is the necessity of matching $B_{1}=B_{2}$ for control of $R_{\mathrm{i}}$ without influence on $k_{\mathrm{i}}$ in both solutions. Solutions with VCA-s and DT-s from Fig.6a and Fig.7a solve this problem and no matching condition is required. However, the gainbandwidth is lower, because VCA810 has lower GBW (30 $\mathrm{MHz}$ only [28]).

\section{CONCLUSION}

We designed and analyzed different varieties of circuit solutions that model current follower (or amplifier) and showed their performances. These circuits could be used as simulation models and mainly experimental (laboratory) models in development of applications with current active elements. They are useful in cases when we do not have any possibilities to fabricate current amplifiers or followers in specific applications like current-mode and mixed-mode filters, oscillators, sensor technique [30-31] (mainly in current-mode), and other circuits in complex systems (for example [32]) and in the first phase of tests (verification of expected behavior). Beyond using powerful simulation programs it allows to reveal important problems in the design without expensive fabrication of chip. Therefore, the presented approaches offer an easy way how to verify the proposed application using special active element with discussed features in a very simple and low-cost solution. 
Because EL2082 multiplier is classified as an obsolete part, two further approaches based on voltage controllable voltage amplifiers and diamond transistors (these parts are easily accessible) were tested and they provided similar benefits. We hope that the presented approaches will be helpful for design, modeling and experiments employing novel types of active elements, which are using the discussed methods of control $\left(k_{\mathrm{i}}, R_{\mathrm{i}}\right)$. Several application examples of such elements were given in [33].

\section{ACKNOWLEDGEMENT}

Research described in the paper was supported by Czech Science Foundation projects under No. 102/09/1681 and No. $102 / 11 /$ P489. The support of the project CZ.1.07/2.3.00/20.0007 WICOMT, financed from the operational program Education for competitiveness, is gratefully acknowledged. Dr. Norbert Herencsar was supported by the project CZ.1.07/2.3.00/30.0039 of Brno University of Technology. The described research was performed in laboratories supported by the SIX project; the registration number CZ.1.05/2.1.00/03.0072, the operational program Research and Development for Innovation.

\section{REFERENCES}

[1] Biolek, D., Senani, R., Biolkova, V., Kolka, Z. (2008). Active elements for analog signal processing: Classification, review, and new proposal. Radioengineering, 17 (4), 15-32.

[2] Fabre, A., Saaid, O., Wiest, F., Boucheron, C. (1996). High frequency applications based on a new current controlled conveyor. IEEE Transactions on Circuits and Systems I: Fundamental Theory and Applications, 43 (2), 82-91.

[3] Siripruchyanun, M., Chanapromma, C., Silapan, P., Jaikla, W. (2008). BiCMOS current-controlled current feedback amplifier (CC-CFA) and its applications. WSEAS Transactions on Electronics, 6 (5), 203-219.

[4] Sedra, A., Smith, K.C. (1970). A second generation current conveyor and its applications. IEEE Transaction on Circuit Theory, 17 (1), 132-134.

[5] Svoboda, J.A., McGory, L., Webb, S. (1991). Applications of a commercially available current conveyor. International Journal of Electronics, 70 (1), 159-164.

[6] Surakampontorn, W., Thitimajshima, W. (1988). Integrable electronically tunable current conveyors. IEE Proceedings G: Electronic Circuits \& Systems, 135 (2), 71-77.

[7] Fabre, A., Mimeche, N. (1994). Class A/AB secondgeneration current conveyor with controlled current gain. Electronics Letters, 30 (16), 1267-1268.

[8] Minaei, S., Sayin, O.K., Kuntman, H. (2006). A new CMOS electronically tunable current conveyor and its application to current-mode filters. IEEE Transaction on Circuits and Systems I: Regular Papers, 53 (7), 1448-1457.

[9] Mahmoud, S., Hashies, M., Soliman, A. (2005). Lowvoltage digitally controlled fully differential current conveyor. IEEE Transactions on Circuits and Systems I: Regular Papers, 52 (10), 2055-2064.
[10] Kumngern, M., Chanwutium, J., Dejhan, K. (2010). Electronically tunable multiphase sinusoidal oscillator using translinear current conveyors. Analog Integrated Circuits and Signal Processing, 65 (2), 327-334.

[11] Sedighi, B., Bakhtiar, M.S. (2007). Variable gain current mirror for high-speed applications. IEICE Electronics Express, 4 (8), 277-281.

[12] Tangsrirat, W. (2008). Electronically tunable multiterminal floating nullor and its application. Radioengineering, 17 (4), 3-7.

[13] Tangsrirat, W., Pukkalanun, T. (2009). Digitally programmable current follower and its applications. AEU - International Journal of Electronics and Communications, 63 (5), 416-422.

[14] Alzaher, H., Tasadduq, N. (2009). Realizations of CMOS fully differential current followers/amplifiers. In IEEE International Symposium on Circuits and Systems (ISCAS 2009), 24-27 May, 2009. IEEE, 13811384.

[15] Alzaher, H., Tasadduq, N., Al-Ees, O., Al-Ammari, F. (2011). A complementary metal-oxide semiconductor digitally programmable current conveyor. International Journal of Circuit Theory and Applications. Accepted for publication (2011). DOI: 10.1002/cta.786.

[16] Koton, J., Herencsar, N., Jerabek, J., Vrba, K. (2010). Fully differential current-mode band-pass filter: Two design solutions. In Proceedings of the 33rd International Conference on Telecommunications and Signal Processing (TSP 2010), 17-20 August, 2010, 1-4.

[17] Biolek, D., Bajer, J., Biolkova, V., Kolka, Z., Kubicek, M. (2010). Z copy-controlled gain-current differencing buffered amplifier and its applications. International Journal of Circuit Theory and Applications, 39 (3), 257-274.

[18] Biolek, D., Lahiri, A., Jaikla, W., Siripruchyanun, M., Bajer, J. (2011). Realisation of electronically tunable voltage-mode/current-mode quadrature sinusoidal oscillator using ZC-CG-CDBA. Microelectronics Journal, 42 (10), 1116-1123.

[19] Herencsar, N., Lahiri, A., Vrba, K., Koton, J. (2012). An electronically tunable current-mode quadrature oscillator using PCAs. International Journal of Electronics, 99 (5), 609-621.

[20] Sotner, R., Jerabek, J., Prokop, R., Vrba, K. (2011). Current gain controlled CCTA and its application in quadrature oscillator and direct frequency modulator. Radioengineering, 20 (1), 317-326.

[21] Marcellis, A., Ferri, G., Guerrini, N.C., Scotti, G., Stornelli, V., Trifiletti, A. (2009). The VGC-CCII: A novel building block and its application to capacitance multiplication. Analog Integrated Circuits and Signal Processing, 58 (1), 55-59.

[22] Kumngern, M., Junnapiya, S. (2010). A sinusoidal oscillator using translinear current conveyors. In IEEE Asia Pacific Conference on Circuits and Systems (APPCAS 2010), 6-9 December 2010. IEEE, 740-743. 
[23] Sotner, R., Herencsar, N., Jerabek, J., Koton, J., Dostal, T., Vrba, K. (2012). Quadrature oscillator based on modified double current controlled current feedback amplifier. In Radioelektronika 2012: Proceedings of 22nd International Conference. IEEE, 275-278.

[24] Jaikla, W., Lahiri, A. (2011). Resistor-less currentmode four-phase quadrature oscillator using CCCDTAs and grounded capacitors. AEU International Journal of Electronics and Communications, 66 (3), 214-218.

[25] Texas Instruments. (1993). OPA633: High speed buffer amplifier. Last modified 9/2000.

[26] Texas Instruments. (1996). BUF634: 250 mA Highspeed buffer. Last modified 9/2000.

[27] Intersil (Elantec). (1996). EL2082: Current-mode multiplier. Last modified 2003.

[28] Texas Instruments. (2003). VCA810: High gain adjust range, wideband, variable gain amplifier. Last modified 12/2010.
[29] Texas Instruments. (2005). OPA860: Wide bandwidth operational transconductance amplifier and buffer. Last modified 8/2008.

[30] Odon, A. (2010). Modelling and simulation of the pyroelectric detector using MATLAB/Simulink. Measurement Science Review, 10 (6), 195-199.

[31] Deng, X., Yang, W.Q. (2012). Fusion research of electrical tomography with other sensors for two-phase flow measurement. Measurement Science Review, 12 (2), 62-67.

[32] Abu-Al-Aish, A., Rehman, M., Abdullah, Z., AbuHassan, H. (2010). Microcontroller based capacitive mass measuring system. Measurement Science Review, 10 (1), 15-18.

[33] Sotner, R., Jerabek, J., Herencsar, N., Dostal, T., Vrba, K. (2011). Additional approach to the conception of current follower and amplifier with controllable features. In Proceedings of the 34th International Conference on Telecommunications and Signal Processing (TSP 2011), 279-283.

Received July 02, 2012. Accepted November 25, 2012. 